\title{
Kinerja Sistem Kotak Pendingin Peltier Tenaga Surya Untuk Penyimpanan Sayur dan Buah
}

\author{
Terang UHS Ginting Manik, Tulus Burhanuddin Sitorus*, Ferry Sembiring \\ Departemen Teknik Mesin, Fakultas Teknik, Universitas Sumatera Utara \\ Jl. Almamater Kampus USU Medan, 20155, Telp. 061-8213250 \\ *E-mail: tburhanudin@yahoo.com
}

\begin{abstract}
The purpose of this study is to determine the performance of peltier cooling box system that utilizes solar power for vegetable and fruit storage. The advantage of the peltier cooling system is that it consumes no electricity and is environmentally friendly. Thermoelectric components are coupled with heat sinks where the small fan are placed on the outside and another fan is placed inside the cooler. The temperature distribution data of peltier cooling system is then analyzed to obtain its performance. Experiments are done in the open spaces that experience exposure to solar radiation. The process of measuring weather conditions is carried out using a weather gauge and to record the temperature distribution on each component of the peltier cooling system used thermocouples connected to the acquisition data. Experimental results show that the minimum temperature that can be achieved on cooled objects such as vegetables and fruits is $17,324^{\circ} \mathrm{C}$. The average temperature of vegetables and fruits during testing ranges from $22^{\circ} \mathrm{C}$. The results of this experiment indicate that the peltier coolant box can be used to maintain the freshness of vegetables and fruits. The maximum COP value of the peltier cooling system was 0.0670 and the minimum COP value was 0.0428 .
\end{abstract}

Keyword: peltier, cooling box, performance, solar power, vegetable and fruit

\section{Abstrak}

Tujuan penelitian ini adalah untuk mengetahui kinerja sistem kotak pendingin peltier yang memanfaatkan tenaga surya untuk penyimpanan sayuran dan buah. Keuntungan dari sistem pendingin peltier adalah tidak mengkonsumsi listrik dan ramah lingkungan. Komponen termoelektrik digabungkan dengan heat sink dimana kipas kecil ditempatkan di luar dan kipas yang lainnya ditempatkan di dalam kotak pendingin. Data pengukuran distribusi temperatur dari sistem pendingin peltier kemudian dianalisis untuk mendapatkan performansinya. Pengujian dilakukan di ruang terbuka yang mengalami paparan radiasi matahari. Proses pengukuran kondisi cuaca dilakukan menggunakan alat pengukur cuaca. Untuk merekam distribusi temperatur pada setiap komponen sistem pendingin peltier digunakan termokopel yang terhubung ke data akuisisi. Hasil eksperimen menunjukkan bahwa temperatur minimum yang dapat dicapai pada objek yang didinginkan yaitu sayuran dan buah-buahan adalah $17.324^{\circ} \mathrm{C}$. Temperatur rata-rata sayuran dan buah-buahan selama pengujian berkisar $22^{\circ} \mathrm{C}$. Hasil pengujian menunjukkan bahwa kotak pendingin peltier dapat digunakan untuk menjaga kesegaran sayuran dan buah-buahan. Nilai COP maksimum dari sistem pendingin peltier yang diuji adalah 0,0670 dan nilai COP minimum adalah 0,0428.

Kata kunci: peltier, kotak pendingin, kinerja, tenaga surya, sayur dan buah

\section{Pendahuluan}

Berdasarkan penelitian yang telah dilakukan selama ini bahwa sebagian besar daerah di Indonesia akan selalu terkena sinar radiasi matahari selama 10-12 jam setiap hari serta diperkirakan jumlah radiasi matahari rata-rata yang sampai di bumi Indonesia berkisar $4,8 \mathrm{kWh} / \mathrm{m}^{2} /$ hari $[1,2,3]$. Salah satu peralatan yang digunakan untuk memanfaatkan radiasi matahari adalah sel fotovoltaik atau panel surya. Secara umum teknologi sel fotovoltaik memiliki keuntungan yaitu biaya pengoperasian dan perawatan yang murah [4]. Sel fotovoltaik merupakan suatu perangkat yang mengubah energi radiasi matahari ke dalam bentuk energi listrik. Dalam penggunaannya, sel fotovoltaik disusun saling berhubungan untuk menghasilkan energi yang lebih banyak dan daya yang besar yang dikenal dengan istilah panel atau modul sel fotovoltaik. Arus yang dihasilkan dari sel fotovoltaik pada umumnya adalah Direct Current (DC) tetapi dengan menggunakan konverter maka arus ini dapat dibuat menjadi Alternating Current (AC).

Permintaan sel fotovoltaik seperti untuk pembangkit energi meningkat setiap waktu di seluruh dunia karena pertimbangan peningkatan kesadaran tentang pemanasan global dan harga perbandingan energi surya dengan pembangkit listrik termal konvensional yang cukup kompetitif [5]. Salah satu sistem pendingin yang dapat memanfaatkan radiasi matahari melalui sel fotovoltaik adalah sistem pendingin peltier. Mesin pendingin peltier tenaga surya merupakan mesin pendingin yang menggunakan energi surya sebagai pengganti energi konvensional untuk menggerakkan peralatan peltier agar dapat digunakan untuk mendinginkan suatu ruangan atau objek [6]. Secara umum, 
komponen utama dari mesin atau kotak pendingin peltier tenaga surya adalah meliputi modul peltier, sel fotovoltaik, kotak pendingin, isolator, permukaan bersirip (heat sink) dan kipas pendingin. Energi listrik yang dihasilkan oleh sel fotovoltaik disuplai ke mesin pendingin peltier melalui efek fotovoltaik (photovoltaic effect).

Penelitian ini bertujuan untuk mengetahui performansi sistem kerja kotak pendingin peltier tenaga surya untuk penyimpanan sayur dan buah. Sistem pendingin peltier (thermo electric cooler) merupakan suatu komponen pendingin solid state elektrik yang dapat berfungsi sebagai pemompa panas untuk melakukan proses pendinginan. Prinsipnya dengan menggunakan efek peltier dimana sisi dingin (cold side) digunakan untuk tujuan pendinginan dan sisi panas (hot side) digunakan untuk membuang panas dari sisi dingin ke lingkungan dengan memanfaatkan heat sink dan kipas pendingin [7]. Pada bagian sisi sistem pendingin peltier yang menyerap panas maka terjadi efek pendinginan dan hal inilah yang dimanfaatkan untuk berbagai proses pendinginan. Dikatakan sistem pendingin peltier karena sistem ini memanfaatkan efek Peltier yang pertama kali ditemukan oleh Jean Charles Antanase Peltier pada tahun 1834. Secara singkat dapat dikatakan bahwa efek Peltier merupakan suatu efek timbulnya panas pada satu sisi dan timbulnya dingin pada sisi yang lain saat arus listrik Direct Current dilewatkan kepada rangkaian dari dua tipe material berbeda yang dihubungkan [8].

Material tersebut adalah material thermo electric element yang dibuat dari bahan semi konduktor. Secara umum kelebihan dari sistem pendingin peltier adalah praktis karena bentuknya yang kecil, instalasinya mudah, tidak melibatkan pendukung-pendukung mekanik yang besar dan rumit, dapat diterapkan pada perangkat pendingin portable, tidak mudah rusak, serta diprediksi mampu untuk digunakan berkisar 100.000 jam. Sedangkan kekurangannya adalah keterbatasan kemampuan pendinginan dan efisiensinya yang rendah. Perlu diketahui bahwa efisiensi sistem pendingin peltier berkisar 10-15\% [9]. Aplikasi yang sering digunakan oleh sistem pendingin peltier adalah dengan memanfaatkan temperatur bagian dingin yang dihasilkan yaitu sebagai pendingin processor, AC mini, kulkas pada dispenser, pendingin minuman, dan pengatur temperatur akuarium. Sedangkan temperatur bagian panasnya dapat dibuang dengan memasangkan heat sink dan kipas. Besarnya koefisien performansi (COP) peltier adalah perbandingan antara kalor yang dihasilkan peltier dengan energi yang disuplai. Nilai dari COP peltier dapat ditentukan dari persamaan [10]:

$$
\mathrm{COP}=\frac{\mathrm{Q}_{\text {pendingina }}}{\mathrm{W}_{\mathrm{in}}}
$$

Besarnya kapasitas pendinginan yang terjadi (W) adalah

$$
\mathrm{Q}_{\text {pendinginan }}=\mathrm{m} \cdot \mathrm{c}_{\mathrm{p}} \cdot \Delta \mathrm{t}(\mathrm{W})
$$

dan $\mathrm{W}_{\text {in }}$ merupakan besarnya energi yang digunakan untuk menggerakkan komponen peltier (W).

\section{Material dan Metode Penelitian}

\subsection{Bahan}

Pada penelitian ini, kotak pendingin yang dirakit menggunakan elemen pendingin peltier sebanyak empat buah jenis TEC1-12706 dengan tegangan $12 \mathrm{~V}$ dan arus $6 \mathrm{~A}$. Dua buah baterai digunakan untuk memberikan daya listrik ke komponen peltier yang terdapat pada kotak pendingin. Untuk memberikan suplai daya ke baterei dengan sumber energi matahari maka digunakan dua buah modul panel surya. Pengatur tegangan SCC (Solar Charge Controller) digunakan untuk mengatur arus untuk pengisian dari panel surya ke baterai untuk menghindari kelebihan pengecasan (overcharging) dan kelebihan tegangan (overvoltage) serta memonitoring temperatur baterai. SCC yang digunakan berjumlah satu buah dengan tegangan $12 \mathrm{~V}$ dan arus $10 \mathrm{~A}$. Pada penelitian ini digunakan sayur dan buah sebagai objek yang didinginkan. Untuk meminimalisir pengaruh udara luar maka kotak pendingin sistem peltier diisolasi dengan triplek setebal $10 \mathrm{~mm}$ pada bagian luar, styrofoam dengan tebal $40 \mathrm{~mm}$ pada bagian tengah, plat stainless steel setebal 1 $\mathrm{mm}$ dan dilapsi dengan aluminium foil pada bagian dalam. Untuk lebih merapatkan bagian penutup kotak pendingin maka pada tutup bagian atas dipasang baut pengikat yang dapat dibuka tutup.

\subsection{Skema Eksperimental}

Proses pengujian dilakukan mulai dari pukul 09.00 WIB dimana suplai daya dari baterai mulai diaktifkan. Data akuisisi Cole Parmer terhubung dengan termokopel tipe J dengan akurasi $\pm 0,4 \%$ digunakan untuk mengukur distribusi temperatur yang terjadi di dalam kotak pendingin. Data akuisisi bekerja secara otomatis dan merekam hasil pengukuran dalam bentuk program excel untuk setiap menit. Untuk merekam kondisi cuaca digunakan alat ukur cuaca yang terdiri dari pyranometer (akurasi $\pm 5 \%$ ) untuk mengukur radiasi matahari, temperature smart sensor (akurasi $\pm 0,2^{\circ} \mathrm{C}$ ) untuk mengukur temperatur lingkungan dan RH smart sensor (akurasi $\pm 2,5 \%$ ) untuk mengukur kelembaban udara. Kotak pendingin dan baterei dinonaktifkan pada pukul 17.00 WIB. Baterai kembali diaktifkan pukul 09.00 WIB pada esok harinya dan pengujian dilakukan kembali dengan prosedur yang sama. Pengujian dilakukan selama 3 hari berturut-turut pada bulan September 2017 di kota Medan. Tabel 1 menampilkan spesifikasi dari instalasi sistem kotak pendingin peltier yang dirancang. 
Tabel 1. Spesifikasi instalasi sistem kotak pendingin peltier

\begin{tabular}{cll}
\hline No & Data & Keterangan \\
\hline 1 & Dimensi kotak pendingin & panjang $36 \mathrm{~cm}$, lebar $28 \mathrm{~cm}$, tinggi $26 \mathrm{~cm}$ \\
2 & Tipe / jumlah peltier & TECl-12706 / 4 buah @ 72 watt \\
3 & Jumlah heat sink / cold sink & Masing-masing 4 buah \\
4 & Jumlah kipas pendingin & 4 buah @ 1,8 watt \\
5 & Jumlah sel panel surya & 2 buah @ 100 watt \\
6 & Media yang didinginkan & sayur dan buah \\
7 & Bahan kotak pendingin & triplek, styrofoam, stainless steel, aluminium foil \\
\hline
\end{tabular}

Gambar 1 menampilkan bentuk bagian luar dan bagian dalam dari kotak pendingin peltier yang diuji sedangkan Gambar 2 menunjukkan skema eksperimental yang dilakukan.
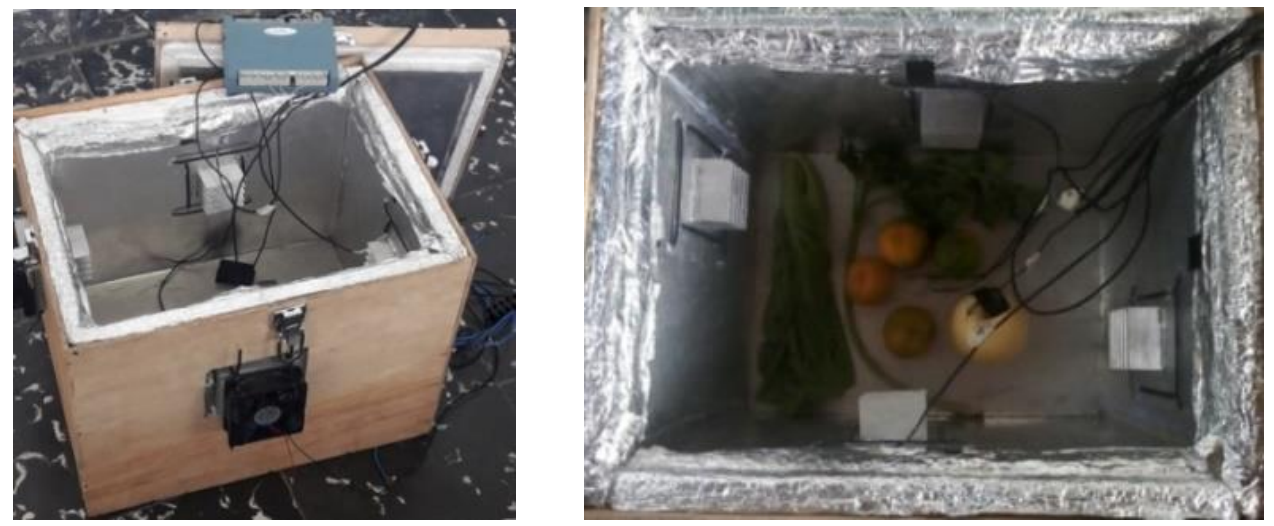

Gambar 1. Bentuk bagian luar dan dalam dari sistem kotak pendingin peltier

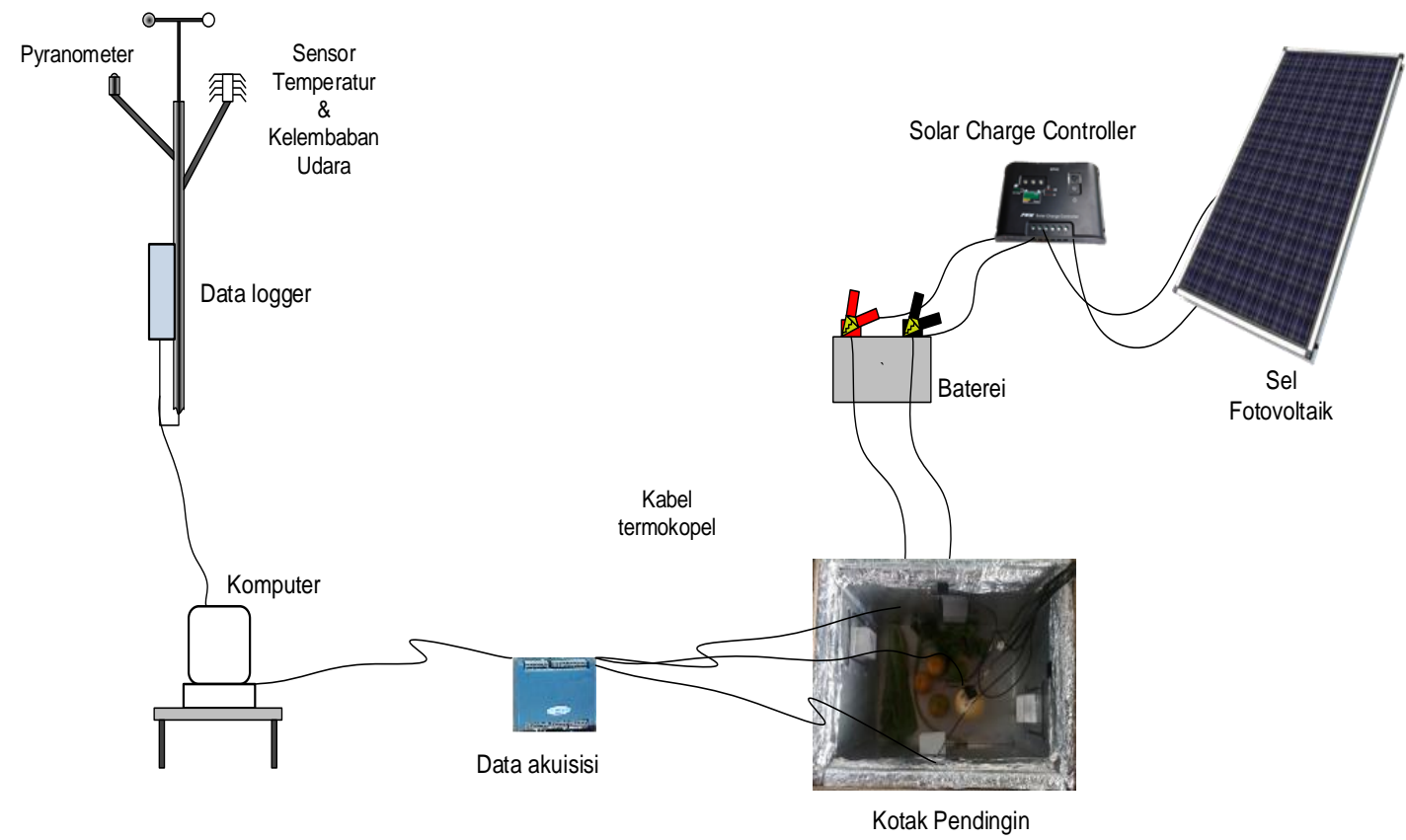

Gambar 2. Skema eksperimental penelitian

\section{Hasil dan Pembahasan}

\subsection{Kondisi Cuaca Saat Pengujian}

Proses eksperimental dilaksanakan di lokasi terbuka yang mengalami radiasi matahari langsung. Kondisi cuaca perlu diketahui karena terkait dengan performansi dari sel fotovoltaik yang digunakan. Sel fotovoltaik digunakan untuk menyerap energi radiasi matahari dan disimpan ke baterai. Komponen baterai digunakan sebagai sumber energi untuk menggerakkan komponen peltier pada proses pendinginan. Proses pengukuran kondisi cuaca dilakukan selama tiga hari pengujian. Rentang waktu pengukuran dilakukan setiap satu menit. Tabel 2 menunjukkan kondisi rata-rata parameter 
cuaca selama proses pengujian. Pada penelitian ini, parameter cuaca yang diukur adalah temperatur lingkungan, kelembaban udara dan intensitas radiasi matahari.

Tabel 2. Kondisi cuaca selama pengujian

\begin{tabular}{cccc}
\hline Hari & $\begin{array}{c}\text { Temperatur udara } \\
\text { rata-rata }\left({ }^{\circ} \mathrm{C}\right)\end{array}$ & $\begin{array}{c}\text { Kelembaban udara } \\
\text { rata-rata }(\%)\end{array}$ & $\begin{array}{c}\text { Radiasi matahari } \\
\text { rata-rata }\left(\mathrm{W} / \mathrm{m}^{2}\right)\end{array}$ \\
\hline 1 & 31.593 & 63,06 & 187,23 \\
2 & 30,586 & 79,21 & 178,22 \\
3 & 30,229 & 81,87 & 165,32 \\
\hline
\end{tabular}

\subsection{Kinerja Panel Surya}

Pengujian sistem kotak pendingin peltier menggunakan komponen sel panel surya untuk menyerap radiasi matahari agar dapat menghasilkan energi listrik. Untuk menghitung estimasi jumlah dan daya modul PV yang diperlukan maka perlu diketahui dahulu besarnya daya yang dibutuhkan oleh sistem kotak pendingin setiap harinya. Pada penelitian ini, digunakan 4 buah kipas angin kecil dan 4 buah komponen peltier tipe TEC1-12706. Besarnya penggunaan listrik ratarata selama 8 jam dalam satu hari adalah 2311,2 watt. Perlu diketahui bahwa untuk perhitungan estimasi jumlah dan daya ini maka diasumsikan kondisi cuaca cerah dengan intensitas radiasi matahari rata-rata 8 jam per hari. Dengan efisiensi dari sistem berkisar 96\% maka jumlah sel PV yang dibutuhkan adalah dua buah. Berdasarkan spesifikasi PV yang digunakan maka diperoleh daya maksimum untuk satu sel PV sebesar 108,60 watt serta efisiensi PV adalah $15,60 \%$. Pada penelitian ini digunakan baterai yang berfungsi untuk menyimpan energi listrik dan digunakan untuk menggerakkan peralatan kipas dan komponen peltier. Baterai yang digunakan pada pengujian ini memiliki spesifikasi $12 \mathrm{~V}$ daya $70 \mathrm{Ah}$. Besarnya tegangan dan arus yang keluar dari panel surya berkisar 18,9 V dan 5,3 A yang selanjutnya diatur oleh SCC menjadi 12 Volt dan 10 A sehingga dapat mengisi baterai 70 Ah.

\subsection{Kinerja Sistem Kotak Pendingin Peltier}

Kinerja dari sistem pendingin peltier diuji dengan menempatkan sensor termokopel pada beberapa titik di kotak pendingin. Titik sensor termokopel diletakkan pada luar kotak pendingin untuk mengetahui temperatur lingkungan, dinding penutup atas, dinding sebelah kiri, dinding sebelah kanan, dinding bawah serta pada objek yang didinginkan yaitu sayur dan buah. Pengujian dilakukan mulai dari pukul 09.00 WIB hingga pukul 17.00 WIB selama delapan jam. Pengujian dilakukan selama tiga hari dengan kondisi cuaca yang bervariasi. Gambar 3, 4 dan 5 menunjukkan distribusi temperatur di dalam sistem kotak pendingin dan temperatur udara luar yang dilakukan selama tiga hari. Pengukuran dilakukan pada bagian dalam sistem kotak pendingin peltier dan kondisi udara luar. Pada bagian dalam kotak pendingin, distribusi temperatur diukur pada dinding sebelah kiri, dinding sebelah kanan, dinding bagian bawah, dinding penutup atas, sayur dan buah.

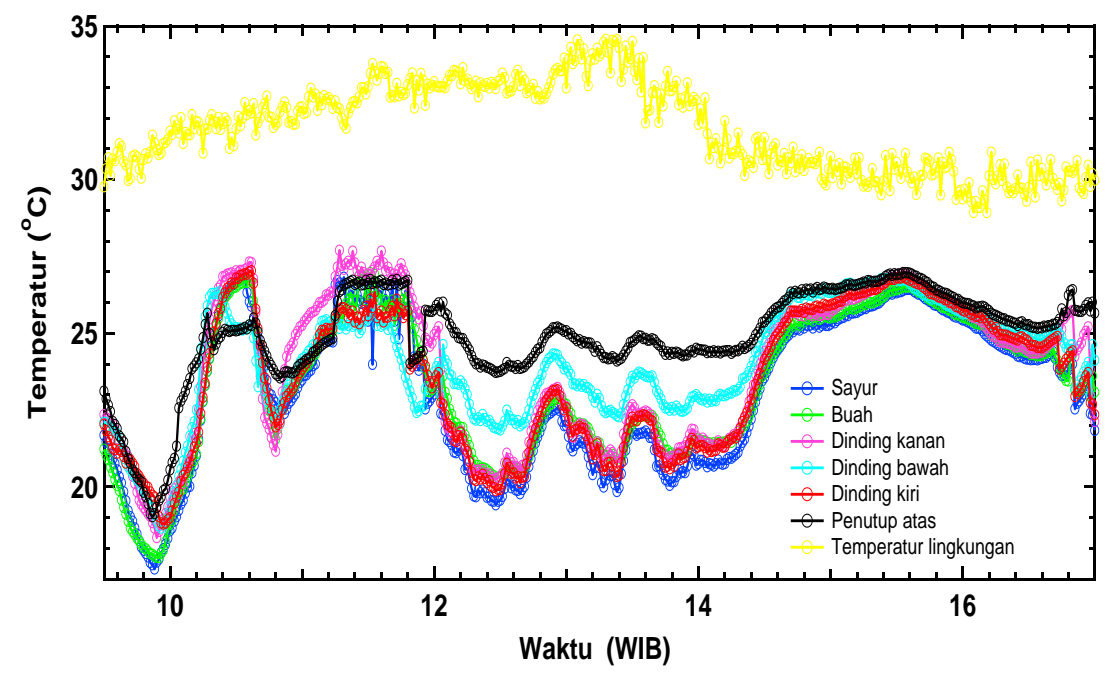

Gambar 3. Distribusi temperatur sistem kotak pendingin peltier untuk hari pertama 


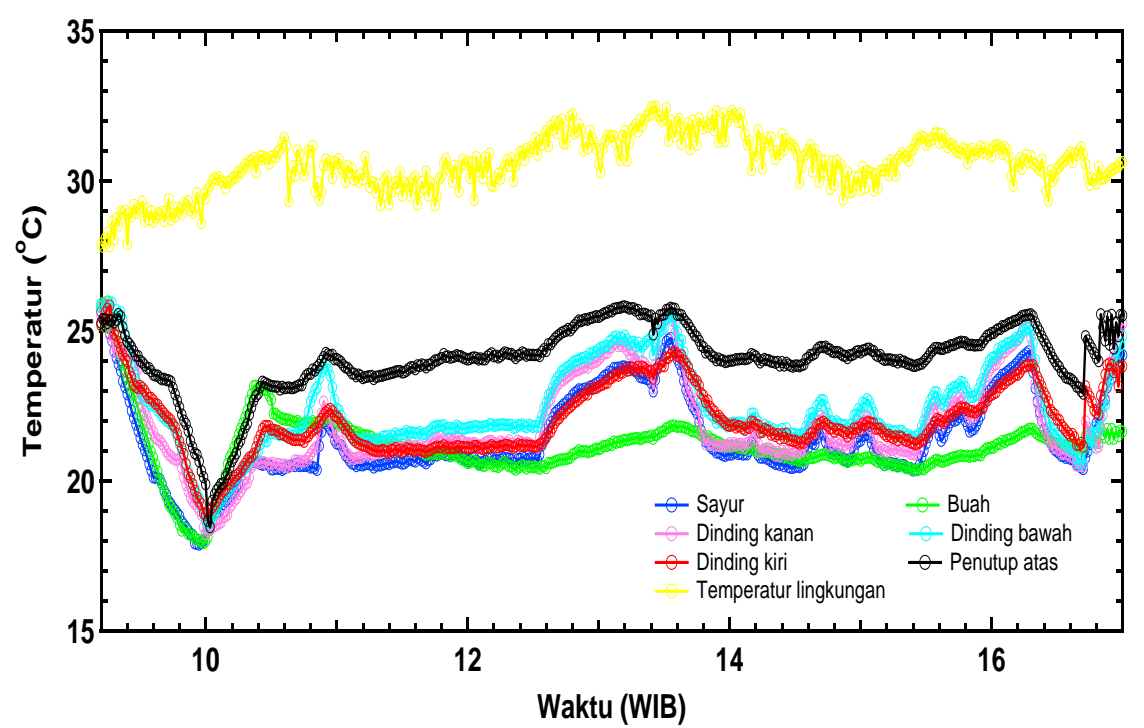

Gambar 4. Distribusi temperatur sistem kotak pendingin peltier untuk hari kedua

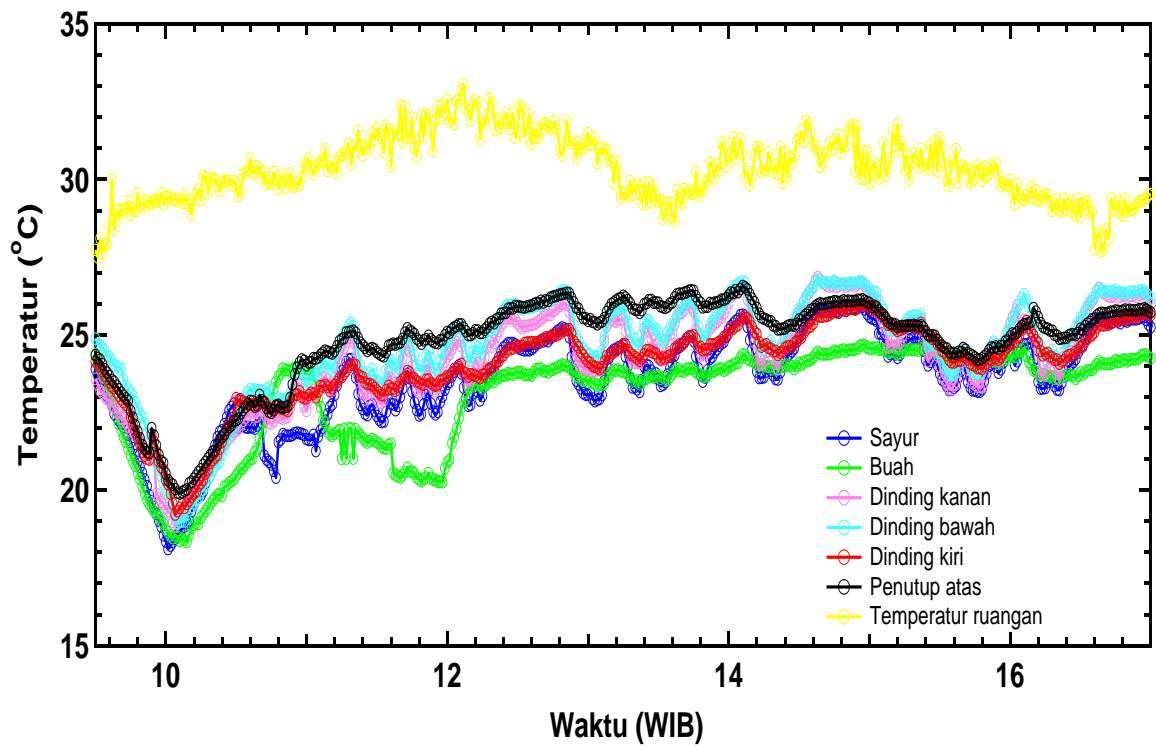

Gambar 5. Distribusi temperatur sistem kotak pendingin peltier untuk hari ketiga

Pada pengujian hari pertama hingga hari ketiga diperoleh temperatur minimum dari sayur berturut-turut adalah $17,324^{\circ} \mathrm{C}, 17,876^{\circ} \mathrm{C}$ dan $18,102^{\circ} \mathrm{C}$. Sedangkan temperatur minimum untuk buah selama tiga hari berturut-turut adalah $17,688^{\circ} \mathrm{C}, 17,923^{\circ} \mathrm{C}$, dan $18,328^{\circ} \mathrm{C}$. Temperatur minimum dari sayur maupun buah diperoleh pada pengujian hari pertama dengan temperatur lingkungan rata-rata $31,593^{\circ} \mathrm{C}$. Umumnya temperatur minimum pada objek sayur dan buah diperoleh pada pukul 09.00 WIB - 10.00 WIB. Besarnya temperatur rata-rata dari sayur dan buah adalah $22^{\circ} \mathrm{C}$ dan temperatur rata-rata dari dinding bagian dalam kotak pendingin selama pengujian berkisar $23^{\circ} \mathrm{C}$. Hasil pengukuran menunjukkan bahwa temperatur rata-rata udara luar pada hari pertama hingga hari ketiga adalah $30,803^{\circ} \mathrm{C}$. Data pengujian juga menunjukkan bahwa temperatur udara lingkungan maksimum yang pernah dicapai selama pengujian adalah $34,566^{\circ} \mathrm{C}$ yang terjadi pada hari pertama. Berdasarkan hasil pengukuran diperoleh bahwa meskipun kecil namun terdapat perbedaan temperatur pada objek yang didinginkan yaitu sayur dan buah. Hal ini dipengaruhi oleh kandungan air pada sayur dan buah yang berbeda. Secara umum terjadi perbedaan distribusi temperatur yang terjadi pada titik komponen yang diukur. Tampak dari gambar 3, 4 dan 5 bahwa distribusi temperatur pada penutup atas lebih tinggi dibandingkan pada distribusi temperatur pada dinding bagian kiri, kanan dan bawah. Hal ini turut dipengaruhi oleh jarak komponen heat sink yang lebih dekat ke dinding sebelah kiri, kanan dan bawah serta radiasi matahari yang langsung ke arah penutup atas.

Data eksperimental menunjukkan bahwa titik pengukuran pada dinding luar sistem kotak pendingin memiliki temperatur yang paling tinggi dibandingkan titik pengukuran lainnya dimana hal ini disebabkan oleh adanya pengaruh dari temperatur udara luar dan pengaruh dari panas yang dibuang oleh kipas dari heatsink yang terpasang ke lingkungan 
sekitar. Data penelitian mengindikasikan bahwa distribusi temperatur di dalam kotak pendingin cukup merata ke semua sisi kotak pendingin. Besarnya perbedaan temperatur di dalam kotak pendingin dengan temperatur udara luar berkisar $14^{\circ} \mathrm{C}-17^{\circ} \mathrm{C}$. Kondisi ini menunjukkan terjadinya proses pembuangan kalor yang terdapat di dalam kotak pendingin ke udara luar sehingga ada efek pendinginan (cooling effect) pada objek yang didinginkan yaitu sayur dan buah. Dari hasil pengukuran juga tampak bahwa secara umum selama tiga hari pengujian terdapat fluktuasi distribusi temperatur pada komponen-komponen yang diukur di dalam kotak pendingin.

Analisa terhadap fluktuasi distribusi temperatur di dalam kotak pendingin tersebut dapat disebabkan beberapa faktor. Pertama, perubahan temperatur udara luar yang turut mempengaruhi kondisi distribusi temperatur di dalam kotak pendingin. Kedua, kinerja dari kipas yang cukup lama digunakan dapat mengakibatkan timbulnya panas di dalam sistem kotak pendingin. Ketiga, berkurangnya suplai energi dari baterai untuk menggerakkan kipas dan komponen peltier pada kotak pendingin sehingga kurang bekerja secara optimal. Pada penelitian ini diperoleh juga nilai COP dari sistem kotak pendingin peltier yang diuji seperti tampak pada tabel 3. Dari hasil eksperimental diperoleh bahwa nilai COP maksimum sebesar 0,0670 saat pengujian hari pertama dengan lama proses pendinginan 41 menit. Besarnya nilai COP yang diperoleh dipengaruhi oleh lama proses pendinginan untuk setiap pengujian dan suplai energi baterai ke komponen peltier. Berdasarkan analisa yang dilakukan bahwa kapasitas baterai berkorelasi dengan radiasi matahari yang diterima sel panel surya. Sedangkan intensitas radiasi matahari sangat dipengaruhi oleh cuaca yang berfluktuasi mengalami kondisi cerah dan mendung.

Tabel 3. Nilai COP yang diperoleh selama pengujian

\begin{tabular}{cccccc}
\hline Hari & $\begin{array}{c}\text { Temperatur awal } \\
\left({ }^{\circ} \mathrm{C}\right)\end{array}$ & $\begin{array}{c}\text { Temperatur minimum } \\
\left({ }^{\circ} \mathrm{C}\right)\end{array}$ & $\begin{array}{c}\text { Lama pendinginan } \\
(\text { menit })\end{array}$ & $\begin{array}{c}\text { Temperatur udara luar rata- } \\
\text { rata }\left({ }^{\circ} \mathrm{C}\right)\end{array}$ & COP \\
\hline 1 & 25,561 & 17,324 & 41 & 31,593 & 0,067 \\
2 & 25,654 & 17,876 & 45 & 30,586 & 0,053 \\
3 & 26,819 & 18,102 & 49 & 30,229 & 0,043 \\
\hline
\end{tabular}

\section{Kesimpulan}

Sistem kotak pendingin peltier telah berhasil dirakit dan diuji kinerjanya. Keuntungan sistem pendingin peltier tenaga surya adalah tanpa menggunakan refrijeran berupa zat kimia sehingga ramah lingkungan dan tanpa menggunakan energi listrik. Pada pengujian selama tiga hari diperoleh temperatur minimum pada objek yang didinginkan yaitu sayur dan buah berkisar $17,324^{\circ} \mathrm{C}$. Sedangkan temperatur rata-rata sayur dan buah selama pengujian berkisar $22^{\circ} \mathrm{C}$. Kondisi ini cukup membuat sayur dan buah tetap segar karena berdasarkan literatur bahwa temperatur rata-rata agar sayur dan buah tetap segar adalah lebih kecil dari temperatur ruangan $25^{\circ} \mathrm{C}$. Hasil pengujian ini menunjukkan bahwa sistem pendingin peltier yang diuji dapat digunakan untuk menjaga kesegaran dari sayur dan buah. Nilai COP maksimum dari sistem pendingin peltier adalah 0,0670 dan nilai COP minimum sebesar 0,0428. Untuk penelitian selanjutnya perlu dipertimbangkan kapasitas baterai untuk menyimpan energi dari sel fotolvotaik karena ini turut mempengaruhi kinerja dari sistem pendingin peltier tersebut.

\section{Ucapan Terima Kasih}

Penulis mengucapkan terimakasih kepada Universitas Sumatera Utara atas bantuan dana yang diberikan melalui proyek penelitian TALENTA tahun 2017.

\section{Daftar Pustaka}

[1] Tulus B. Sitorus, Farel H. Napitupulu, Himsar Ambarita. A Study on Adsorption Refrigerator Driven by Solar Collector Using Indonesian Activated Carbon. Journal of Engineering and Technological Sciences., Vol. 49, No. 5, 2017, 657-670.

[2] T B Sitorus, H Ambarita, F Ariani and T Sitepu. 2018. Performance of the natural cooler to keep the freshness of vegetables and fruits in Medan City. IOP Conf. Series: Materials Science and Engineering 309, 012089.

[3] T. B. Sitorus, F.H. Napitupulu, H. Ambarita. 2016. Experimental Study of Solar Refrigerator System Using Activated Alumina and Methanol Adsorption Pair. International Journal of Technology. IJTech Journal, Vol. 7 Issue 5 pp. 910-922.

[4] Sabah A. Abdul-Wahab, Ali Elkamel, Ali M. Al-Damkhi, Is'haq A. Al-Habsi, Hilal S. Al-Rubai’ey. 2009. Design and Experimental Investigation of Portable Solar Termoelectric Refrigerator. Renewable Energy vol 34 pp. 30-34.

[5] Xi H, Luo L, Fraisse G. 2007. Development and applications of solar-based thermoelectric technologies. Renew Sustain Energy Rev vol 11 pp. 923-36.

[6] Bosen Qian, Fei Ren. 2016. Cooling performance of transverse thermoelectric devices. International Journal of Heat and Mass Transfer vol 95 pp. 787-794

[7] Martinez, D. Astrain, A. Rodriguez, P. Aranguren. 2016. Advanced computational model for Peltier effect based refrigerators. Applied Thermal Engineering vol 95 pp. 339-347. 
[8] Yan-Wei Gao, Hao L, Xiao-Dong Wang, Wei-Mon Yan. 2017. Enhanced Peltier cooling of two-stage thermoelectric cooler via pulse Currents. International Journal of Heat and Mass Transfer vol 114 pp. 656-663.

[9] Eun Soo Jeong. 2005. Optimization of conduction-cooled Peltier current leads. Cryogenics vol 45 pp.516-522.

[10] Christian J.L. Hermes, Jader R. Barbosa Jr. 2012. Thermodynamic comparison of Peltier, Stirling, and vapor compression portable coolers. Applied Energy vol 91 pp. 51-58. 